\title{
Tip Vortex and Wake Characteristics of a Counterrotating Open Rotor
}

Dale E. Van Zante and Mark P. Wernet

Glenn Research Center, Cleveland, Ohio 


\section{NASA STI Program . . . in Profile}

Since its founding, NASA has been dedicated to the advancement of aeronautics and space science. The NASA Scientific and Technical Information (STI) program plays a key part in helping NASA maintain this important role.

The NASA STI Program operates under the auspices of the Agency Chief Information Officer. It collects, organizes, provides for archiving, and disseminates NASA's STI. The NASA STI program provides access to the NASA Aeronautics and Space Database and its public interface, the NASA Technical Reports Server, thus providing one of the largest collections of aeronautical and space science STI in the world. Results are published in both non-NASA channels and by NASA in the NASA STI Report Series, which includes the following report types:

- TECHNICAL PUBLICATION. Reports of completed research or a major significant phase of research that present the results of NASA programs and include extensive data or theoretical analysis. Includes compilations of significant scientific and technical data and information deemed to be of continuing reference value. NASA counterpart of peer-reviewed formal professional papers but has less stringent limitations on manuscript length and extent of graphic presentations.

- TECHNICAL MEMORANDUM. Scientific and technical findings that are preliminary or of specialized interest, e.g., quick release reports, working papers, and bibliographies that contain minimal annotation. Does not contain extensive analysis.

- CONTRACTOR REPORT. Scientific and technical findings by NASA-sponsored contractors and grantees.
- CONFERENCE PUBLICATION. Collected papers from scientific and technical conferences, symposia, seminars, or other meetings sponsored or cosponsored by NASA.

- SPECIAL PUBLICATION. Scientific, technical, or historical information from NASA programs, projects, and missions, often concerned with subjects having substantial public interest.

- TECHNICAL TRANSLATION. Englishlanguage translations of foreign scientific and technical material pertinent to NASA's mission.

Specialized services also include creating custom thesauri, building customized databases, organizing and publishing research results.

For more information about the NASA STI program, see the following:

- Access the NASA STI program home page at http://www.sti.nasa.gov

- E-mail your question to help@sti.nasa.gov

- Fax your question to the NASA STI Information Desk at 443-757-5803

- Phone the NASA STI Information Desk at 443-757-5802

- Write to: STI Information Desk NASA Center for AeroSpace Information 7115 Standard Drive Hanover, MD 21076-1320 
NASA/TM-2012-217713

\section{Tip Vortex and Wake Characteristics of a Counterrotating Open Rotor}

Dale E. Van Zante and Mark P. Wernet

Glenn Research Center, Cleveland, Ohio

Prepared for the

48th Joint Propulsion Conference and Exhibit

cosponsored by AIAA, ASME, SAE, and ASEE

Atlanta, Georgia, July 30 to August 1, 2012

National Aeronautics and

Space Administration

Glenn Research Center

Cleveland, Ohio 44135 


\section{Acknowledgments}

This work was sponsored by the NASA Environmentally Responsible Aviation Project of the Integrated Systems Research Program. The PIV measurement team included Randy Locke, Adam Wroblewski, and Gary Clayo. Csaba Horvath assisted with the figures presenting the PIV data.

Trade names and trademarks are used in this report for identification only. Their usage does not constitute an official endorsement, either expressed or implied, by the National Aeronautics and Space Administration.

Level of Review: This material has been technically reviewed by technical management.

Available from

NASA Center for Aerospace Information 7115 Standard Drive

Hanover, MD 21076-1320
National Technical Information Service 5301 Shawnee Road Alexandria, VA 22312

Available electronically at http://www.sti.nasa.gov 


\title{
Tip Vortex and Wake Characteristics of a Counterrotating Open Rotor
}

\author{
Dale E. Van Zante and Mark P. Wernet \\ National Aeronautics and Space Administration \\ Glenn Research Center \\ Cleveland, Ohio 44135
}

\begin{abstract}
One of the primary noise sources for Open Rotor systems is the interaction of the forward rotor tip vortex and blade wake with the aft rotor. NASA has collaborated with General Electric on the testing of a new generation of low noise, counterrotating Open Rotor systems. Three-dimensional particle image velocimetry measurements were acquired in the intra-rotor gap of the Historical Baseline blade set. The velocity measurements are of sufficient resolution to characterize the tip vortex size and trajectory as well as the rotor wake decay and turbulence character. The tip clearance vortex trajectory is compared to results from previously developed models. Forward rotor wake velocity profiles are shown. Results are presented in a form as to assist numerical modeling of Open Rotor system aerodynamics and acoustics.
\end{abstract}

\section{Nomenclature}

$\begin{array}{ll}\mathrm{X}, \mathrm{Y} & \text { Cartesian PIV coordinates, inches } \\ \mathrm{Z} & \text { Axial PIV coordinate, inches } \\ \text { MSTA } & \text { Model Station axial coordinate, inches } \\ \mathrm{U}, \mathrm{V} & \text { Velocity components in X and Y directions, ft/s } \\ \mathrm{W} & \text { Velocity component (axial) in Z direction, } \mathrm{ft} / \mathrm{s} \\ \mathrm{Vr} & \text { Radial velocity, } \mathrm{ft} / \mathrm{s} \\ \mathrm{Vtheta} & \text { Tangential velocity, ft/s } \\ \text { ORPR } & \text { Open Rotor Propulsion Rig }\end{array}$

\section{Introduction}

The Open Rotor based propulsion system offers the potential for substantial fuel burn reductions, greater than 20 percent, compared to contemporary turbofan based propulsion systems. The increase in fuel costs and greater emphasis on reducing carbon emmisions have both contributed to the renewed interest in Open Rotors.

Open Rotor concepts, previously called propfans, were studied extensively in the 1980s as a result of the oil price shocks of the 1970s. Development advanced as far as flight test engines. For example, the General Electric (GE) Unducted Fan (UDF) engine flew on both MD-80 and 727 airframes. Oil prices stabilized and interest in these radical new engine concepts waned. The UDF program at GE ended in 1989.

The 1980s demonstrator engines were memorable for their unique, scimitar shaped blades, their fuel burn reduction, and their noise levels. Design systems of the time were limited in their ability to optimize for both performance and acoustics simultaneously. The current generation of open rotors have been designed with both three-dimensional aerodynamics tools and computational aeroacoustics tools. This has enabled the new designs to match the best aero performance of the 1980s but with much improved noise characteristics. The goal of the current work is to achieve 15 to 17 EPNdB cumulative margin to the Chapter 4 noise regulations. 
A 1980s design blade set, the Historical Baseline, was remanufactured and tested as part of the current wind tunnel test campaign in the NASA Glenn $9 \times 15$ and $8 \times 6$ wind tunnels using the Open Rotor Propulsion Rig (ORPR). Some details of the $9 \times 15$ wind tunnel are in Reference 1 . Performance and acoustic data from this blade set provides a validation link back to data from the 1980s. Details of previous flowfield data are in Reference 2. The current test program also acquired detailed flow field data from Stereo Particle Image Velocimetry (SPIV) measurements and detailed acoustics measurements from a phased array. In addition, the geometry and data from the Historical Baseline is considered nonproprietary and thus provides a dataset for validation/verification of analysis, simulation and design tools for Open Rotors. Details of the Historical Baseline flow field are presented here for that purpose. The totality of these measurements and geometry details provide a comprehensive database from which design and analysis tools for Open Rotors can be validated.

\section{The Historical Baseline Blade Set}

The Historical Baseline blading, F31/A31, is representative of late 1980s aerodynamic design methodology. The original F31/A31 blade set was tested at NASA Glenn Research Center in the late 1980s with some results reported in Reference 3. The current F31/A31 blades were remanufactured from the original blade coordinates. Figure 1 shows the profile view of the blades. ' $F$ ' refers to the forward blade and 'A' refers to the aft blade. The bladeset is optimized for performance without consideration of acoustics. Table 1 shows some general design parameters for the blading.

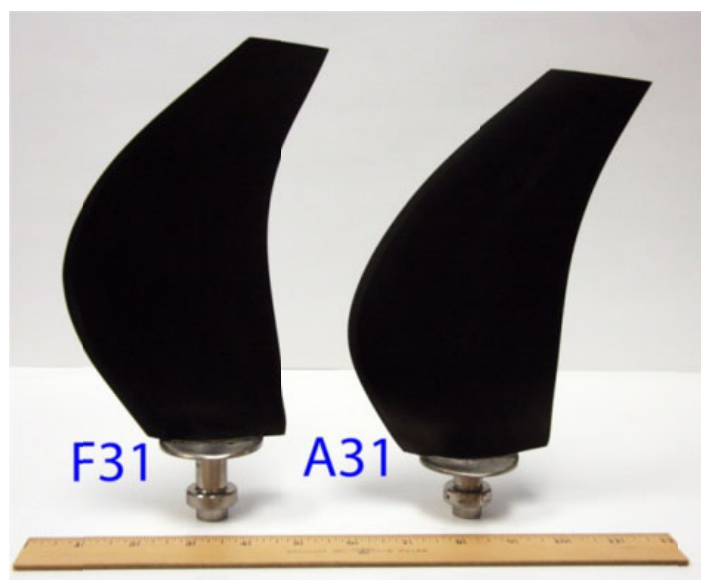

Figure 1.-Profile view of the historical baseline blade set (F31/A31).

TABLE 1.-GENERAL DESIGN PARAMETERS FOR F31/A31

\begin{tabular}{|l|c|c|}
\hline & F31 & A31 \\
\hline Number of blades & 12 & 10 \\
\hline $\begin{array}{l}\text { Nominal tip } \\
\text { Diameter, in. }\end{array}$ & 25.662 & 24.794 \\
\hline $\begin{array}{l}\text { Nominal design } \\
\text { tip speed, } \mathrm{ft} / \mathrm{s}\end{array}$ & 750 & 750 \\
\hline
\end{tabular}




\section{Particle Image Velocimetry System}

For the Open Rotor test, 3-component velocity data were acquired to characterize the tip vorticies emanating from the front rotor and provide blade wake information down to the rotor hub. To provide unobstructed view of the intrablade passage the SPIV system was configured such that the measurement plane of the SPIV cameras was aligned with the circumferential plane and centered at the rig horizontal centerline, see Figure 2. The SPIV system had to be able to obtain planar measurements over a selected range of radial planes between the rotor blades. The cameras were mounted near the floor and ceiling in the wind tunnel test section. In order to facilitate this configuration, two of the acoustic "boxes" in the walls of the $9 \times 15$ were removed and replaced with panels containing the SPIV camera mounts. The panels were equipped with glass viewing ports to minimize any disturbance to the flow and also to minimize any buffeting of the camera hardware.

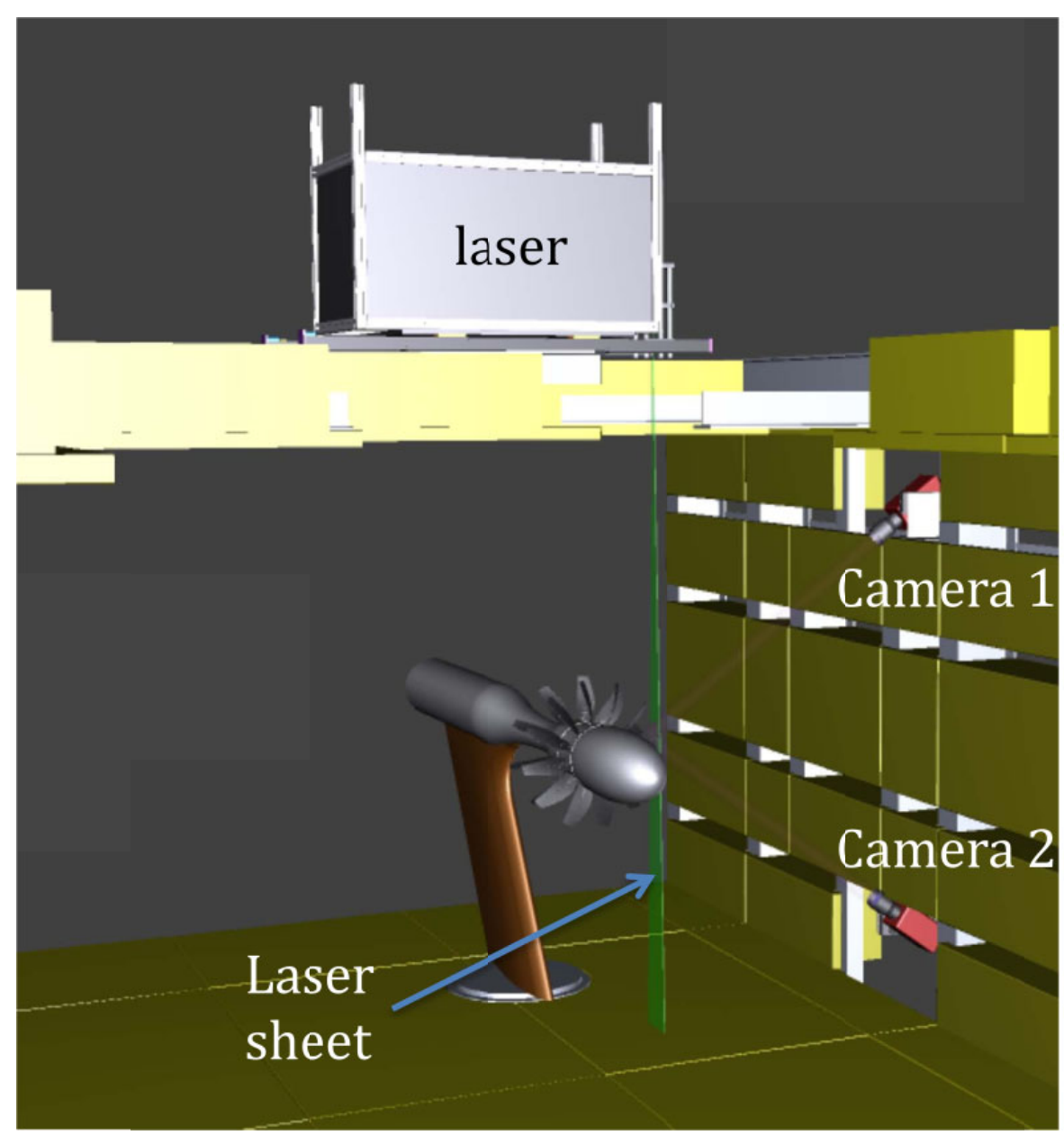

Figure 2.- Stereo PIV system installation in $9 \times 15$ wind tunnel with the ORPR model. The stereo PIV cameras are mounted in the sidewall of the tunnel and the laser system is mounted on the ceiling of the tunnel. The cameras were mounted behind windows located in steel plates (not shown here). 

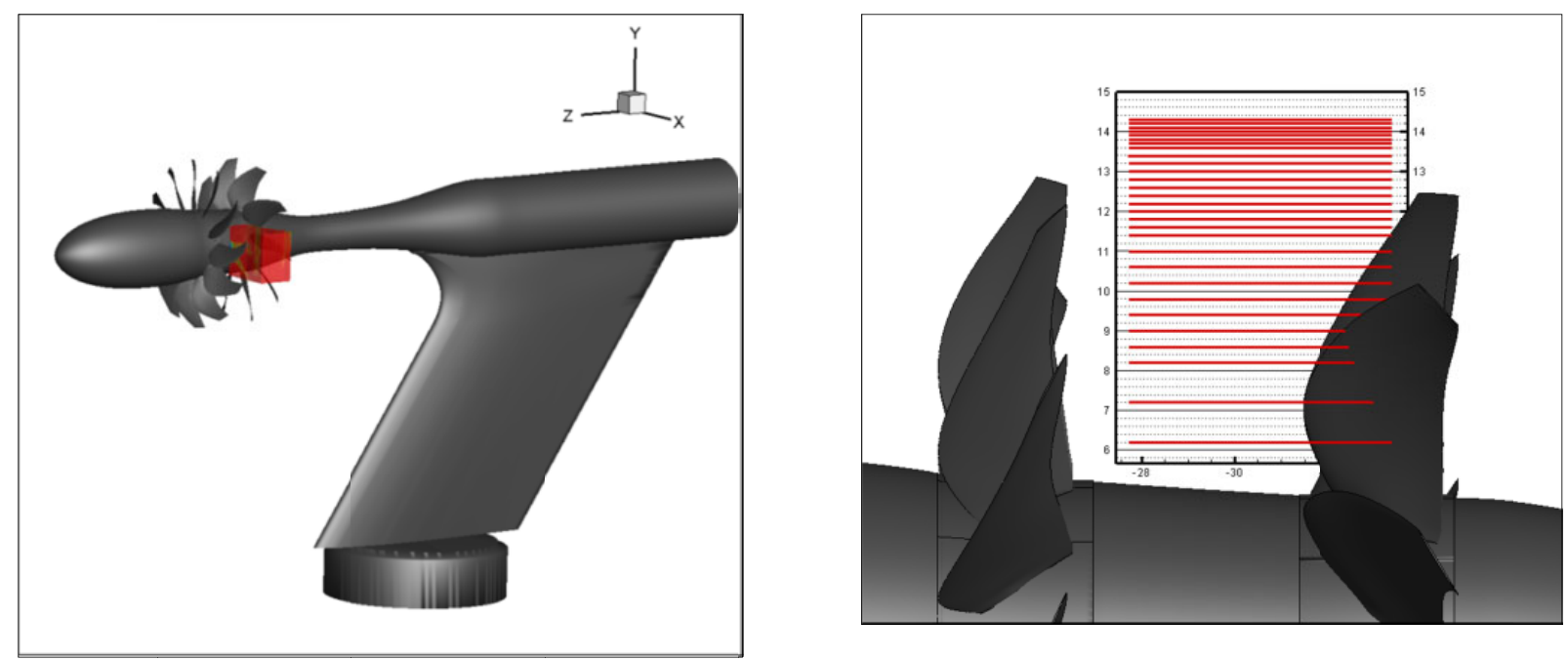

Figure 3.-The left figure shows the PIV measurement volume (in red) relative to the ORPR. The right figure shows the radial location of the measurement planes.

In order to provide the range of measurements from outside of the blade radius down to the rotor hub each camera was mounted on an independent translation stage. Placing the cameras in the tunnel sidewall then dictated that the light sheet originate from the tunnel ceiling in order to provide the quasi-meridional measurement planes. The laser system with light sheet optics was mounted on the top of the wind tunnel, on a third, independent translation stage, as shown in Figure 2. The light sheet entered the tunnel through a specially modified ceiling plate with a glass window port. The PIV system light sheet optics were configured to provide a nearly collimated light sheet having dimensions of $1 \times 150 \mathrm{~mm}$ at the model. A motorized aperture was also used to adjust the light sheet width for portions of the data survey range (in order to avoid hitting the leading edge of the aft blade). The SPIV system employed two Princeton Instruments ES-4020 cameras (2048×2048 pixels) equipped with $180 \mathrm{~mm}$ focal length lenses to provide a $150 \times 200 \mathrm{~mm}$ field of view on the reconstructed velocity fields. The measurement plane was illuminated using a dual head $400 \mathrm{~mJ} /$ pulse Nd:YAG laser system. Both cameras were connected to a single computer system and the data was acquired continuously and streamed to disk at a rate of 10 frame pairs/camera/sec. Although the laser was operated at its design rep rate of $10 \mathrm{~Hz}$, PIV image pair acquisition was limited by the high resolution camera maximum frame pair rate of $5 \mathrm{~Hz}$.

Electromechanical shutters were fitted onto each camera to block the laser light from the intervening laser pulses so that each camera was acquiring frame pairs at $5 \mathrm{~Hz}$. A $1 / \mathrm{rev}$ signal from the model was used to synchronize the PIV data acquisition system with the front rotor on the ORPR. The PIV data were taken asynchronously with respect to the aft rotor. Figure 3 shows the PIV measurement volume relative to the ORPR as well as the radial locations of the measurement planes. The radial spacing of the planes is smaller near the blade tip ( $0.1 \mathrm{in}$.) so that the tip vortex is well defined.

\section{Flow Seeding}

For PIV, the fluid motion being measured is marked by the use of particles introduced into the flow. These particles must be sufficiently small so they will have no slip relative to the fluid (so that their motion is the same as the fluid motion). In addition, all fluid must be laden with particles at a concentration high enough that sufficient particles (5-10) are found in an interrogation region of the recorded PIV images. In this test, strong tip vortices off of the counter-rotating blades were anticipated. Hence, very small seed particles $(<1 \mu \mathrm{m})$ are required in order to faithfully follow the flow field fluctuations. 
In order to seed the flow for the Open rotor tests, a new seed distribution system had to be developed and deployed in the $9 \times 15$ tunnel. The seeder system was selected based on the particle size range and volume of seed produced. Vicount 5500 smoke generators were selected, which generate condensed mineral oil droplets in the range of 0.2 to $0.3 \mu \mathrm{m}$ in diameter at high volumes. The Vicounts work by heating and vaporizing the mineral oil and then expanding it through an orifice using an oxygen free driver gas. When the heated vapor mixes with the ambient air it cools and condenses, forming the seed particles. Since the mixing and cooling of the heated vapor is an essential element in the system operation, care must be used when connecting a Vicount type seeder system to a seed distribution system.

A seeding distribution manifold was used to ensure that the seed material was uniformly dispersed throughout the flow volume encompassing the ORPR model. CFD simulations were run in order to determine the requisite size and location of the distribution manifold so that the fluid volume encompassing the ORPR model in the test section was properly seeded. Two interlaced manifolds were designed, each fed by a single Vicount unit. Each manifold consisted of an array of $8 \mathrm{ft}$ long, $4 \mathrm{in}$. diameter PVC pipes spanning $18 \mathrm{ft}$ in height. The horizontal pipes of the manifolds were interlaced as shown in Figure 4. Since the Vicount smoke generators do not perform well if the seed material is directly piped into the manifold, Coanda Effect ejectors were used to induce a flow in the manifold and provide a local low pressure at the inlet to the manifold pipe. Hence, the seed material from the Vicounts was sucked into the manifold after having a chance to mix with the cool ambient air. A sample PIV image which illustrates the uniform seeding obtained with the new seeder system is shown in Figure 5.

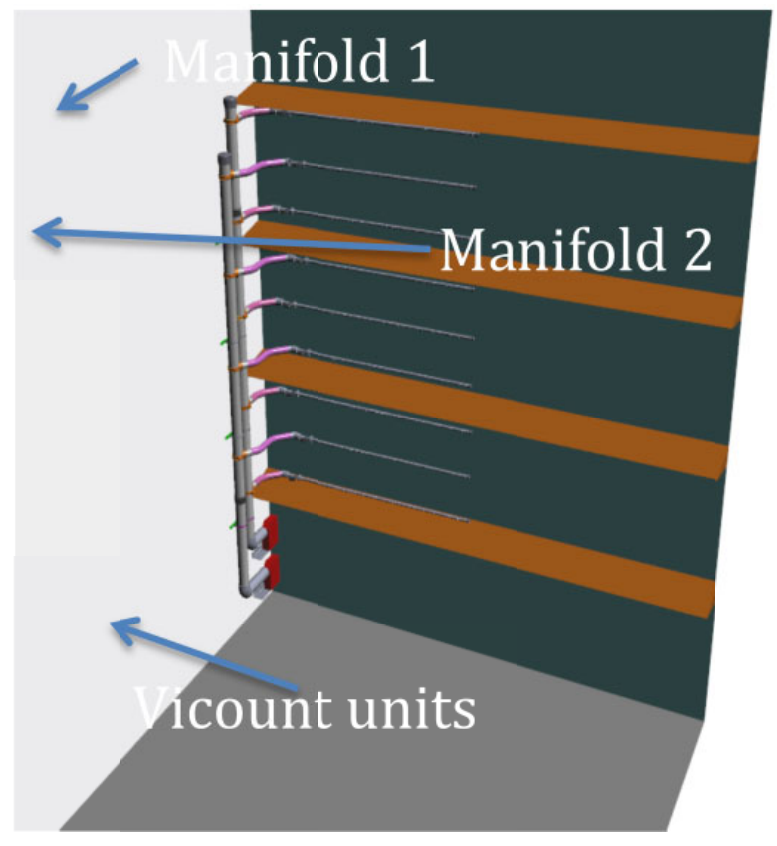

Figure 4.-Downstream view from seeding distribution manifolds which were mounted to the wind tunnel heat exchanger far upstream of the test section. 


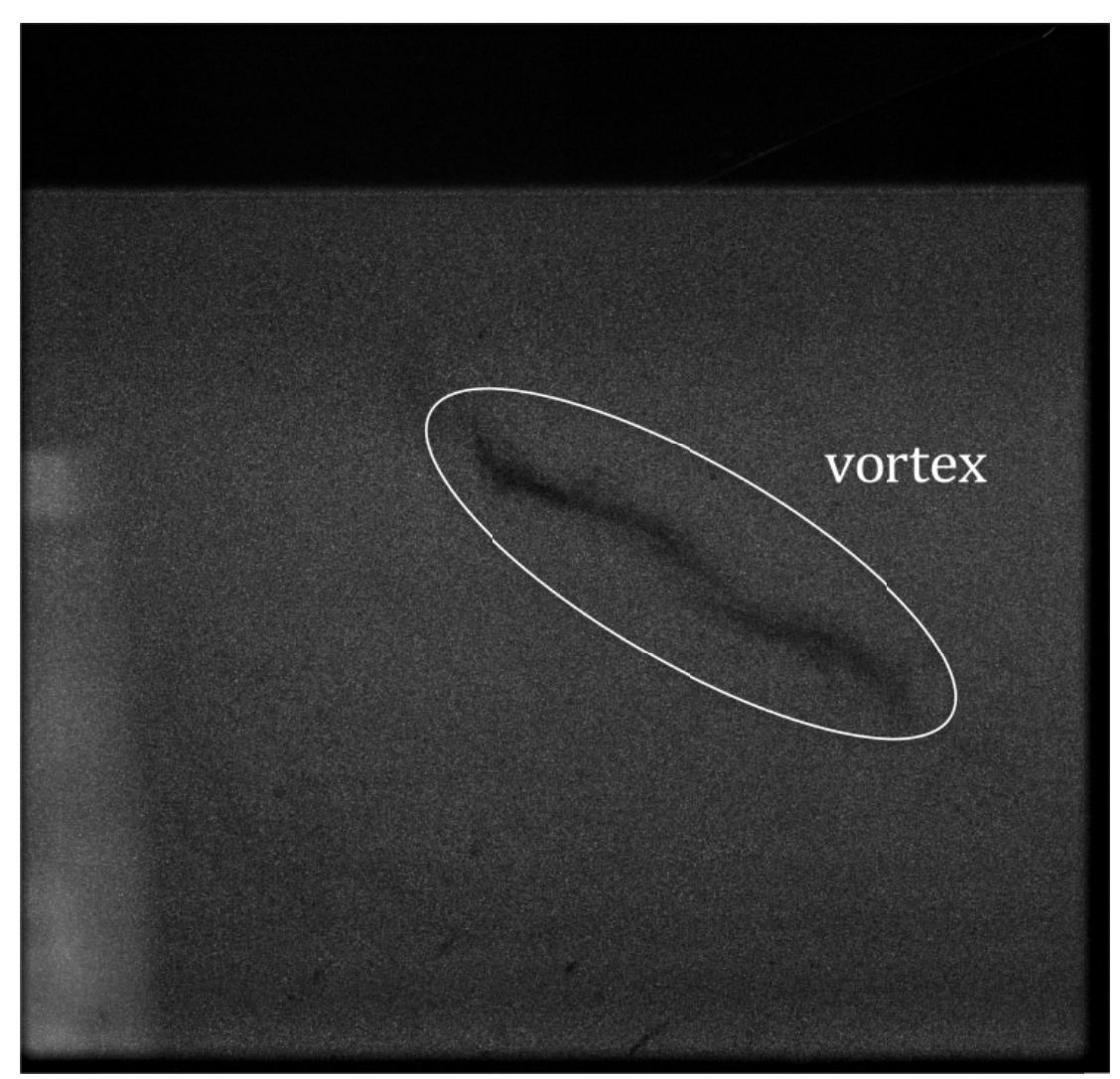

Figure 5.-Sample PIV image showing level of flow seeding. The dark region is a tip vortex. Valid PIV correlations were obtained in all regions of the image.

\section{Stereo PIV Calibration}

When using the stereo PIV technique, a calibration is required for reconstructing the 3-component velocity field from the vector maps computed from the two stereo camera views. This is usually accomplished by traversing a calibration target over 5-planes centered about the light sheet location covering a range of $\pm 2 \mathrm{~mm}$ in $1.0 \mathrm{~mm}$ increments (Ref. 4). This single calibration is then used to compute all of the 3-component vector maps collected in the test program. However, in the ORPR test, each camera is mounted to a separate translation stage and views the light sheet plane through a different window. If the two cameras were perfectly aligned in the same plane and their translation stages moved in exactly the same increments - then a single calibration would suffice. Since this was not physically possible-a unique 5-plane calibration was acquired for each of the 31 measurement planes in the test matrix. Using calibrations for each measurement plane insured that any variations in the camera views were accounted for in the calibrations. The calibrations were performed by yawing the model to the side away from the cameras and installing a calibration jig which was suspended from the laser translation system on top of the tunnel. A metal plate with a grid of $10 \mathrm{~mm}$ dots machined into the front face served as the calibration target. Using the laser translation stage to translate the target ensured that the calibration target was located at the light sheet locations used during the actual measurements. The 3-D PIV calibrations at all of the radial planes were generated with a common coordinate grid so that all of the 3-component vectors maps could be combined into a single block of data (common coordinates).

In addition to using unique calibrations for each measurement plane, a calibration verification operation was performed to ensure that the plane of the light sheet coincided with the calibration plane locations (Ref. 5). The calibration verification operation is performed post test using both recorded image data and the camera calibrations. The corrected calibrations were then used to compute the 3-component velocity field. 


\section{Stereo PIV Data Processing}

The collected SPIV image data were processed using an in-house developed SPIV cross-correlation processing program called PIVPROC (Ref. 6). The correlation based processing software program supports subregion image shifting and multi-pass correlation to improve the spatial resolution of the resultant velocity vector maps. In addition, PIVPROC also supports subregion distortion processing (Ref. 7). In multipass-correlation mode, the correlation processing grid is initially coarse (typically $64 \times 64$ pixel subregions), followed by a higher resolution $2^{\text {nd }}$ pass (typically $32 \times 32$ pixel subregions) in order to improve the spatial resolution of the resulting vector field. The objective of the multi-pass approach is to keep the correlation peak at the center of the correlation plane, which mitigates higher order errors in the correlation peak detection process (Ref. 8). In each pass, PIVPROC uses a spurious peak removal algorithm which removes any vector lying more than three standard deviations from its surrounding 8 neighbors and replaces it with an interpolated value. The estimates for the subregion offsets used in each pass are computed from the previous pass vector map. The offsets are computed from a spatially weighted average of the vector field. PIVPROC uses a simulated annealing approach in the $2^{\text {nd }}$ pass of the multi-pass correlation operation. For example, the first pass correlations were performed at $64 \times 64$ pixel subregions on a $32 \times 32$ pixel grid followed by $2^{\text {nd }}$ pass operations on $32 \times 32$ pixel subregions on a $16 \times 16$ pixel grid. In PIVPROC, a total of 6 passes at the higher grid density can be used, where in each successive pass the region on the correlation plane that is examined for correlation peaks is reduced. In the $6^{\text {th }}$ pass, the correlation plane search region may only be $1 / 3$ of the initial size. Since the subregion image shifting keeps the correlation peak at the center of the correlation plane, this simulated annealing approach reduces the number of spurious vectors by limiting where on the correlation plane that the correlation peaks can be detected. The offsets are computed from the surrounding flow field, so the local flow directs the correlation operation on where to find the correlation peak.

In addition to multi-pass correlation processing, PIVPROC also employs subregion distortion processing (Ref. 7). Subregion distortion processing is used to correct for velocity gradients across the subregion and to minimize the "peak-locking" effect, which is the tendency for the estimated particle displacements to preferentially concentrate at integer values. In the subregion distortion technique, the local velocity gradients surrounding the current correlation subregion are used to distort the subregion before the cross-correlation processing operation. Distorting the subregion yields correlation subregions with uniform particle displacements, and hence, reduces any bias caused by the velocity gradients. Typically, two additional passes after the multi-pass processing are used with subregion distortion applied to refine the correlation peak estimates.

The data were collected to maximize the information content with respect to the tip vortices from the blade tips and also provide blade wake trajectories down to the hub. In the near hub measurements, flare light scattering off of the hub corrupted the PIV image data. Hence, Symmetric Phase Only Filtering (SPOF) correlation processing was used to minimize the data corruption from flare light scattered off of the model (Ref. 9). SPOF is a modification of the traditional cross-correlation processing used in PIV, where the phase information in the frequency domain is emphasized and the image amplitude (flare light) information is suppressed. Combining all of these processing strategies yielded the high quality data sets presented here.

Sequences of 400 velocity vector maps were acquired at each measurement station and ensemble averaged to provide first and second order statistics over the entire measurement plane. Chauvenet's criteria was used to eliminate any outliers in the ensemble averaging process (Ref. 10). All of the processed PIV data were placed in the model coordinate system to facilitate comparison with CFD predictions. The final processed velocity vector maps had an in-plane spatial resolution of $1.43 \mathrm{~mm}$ in both the $\mathrm{x}$ - and $\mathrm{y}$-directions. 


\section{PIV Measurement Accuracy}

The accuracy of the PIV measurement is dependent on several factors. In a well designed experiment, we try to minimize any bias errors, leaving only the random error of the measurement. Use of the mineral oil based seeders produced the smallest aerodynamic diameter particles available for any PIV experiment. Small aerodynamic diameter equates to minimal/no particle lag effects. The Nd:YAG laser has less than 2 nsec jitter in the laser pulse timing, making this error source negligible. Hence, the main factor influencing the measurement accuracy is the particle displacement estimate. Using multi-pass processing ensures that we are obtaining high quality estimates of the particle displacements. Subregion distortion processing further ensures that we are minimizing any biases caused by gradients across the processing subregions or any peak-locking effects. Use of SPOF processing ensures that we can make measurements closer to surfaces than would otherwise be possible. With all of these precautions, the cross-correlation peaks can be nominally estimated to \pm 0.1 pixel. For the processing subregions used here, the maximum displacements were 16 pixels. Hence, the instantaneous PIV measurement accuracy is typically described as $<1$ percent of full scale. Smaller displacements will have lower accuracy than the largest displacements. The use of calibrations for each measurement plane and application of Calibration Verification helps to avoid any bias errors in the estimated velocities. Finally, we collect data sets of 400 measurements which are then ensemble averaged to compute the $1^{\text {st }}$ and $2^{\text {nd }}$ order statistics. Any statistical outliers are removed using Chauvenet's Criteria. Hence, the PIV measurement accuracy presented here are $<1$ percent of full scale.

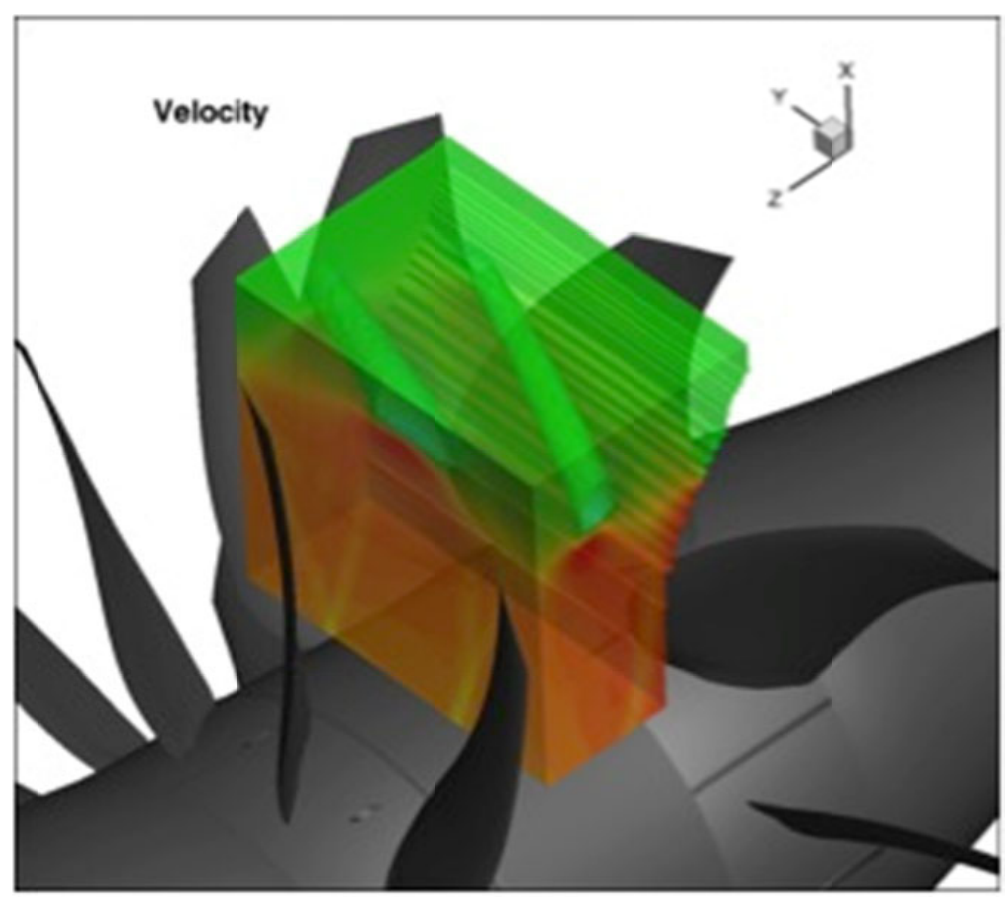

Figure 6.--Representative measurement volume shaded by velocity with the tip vortex highlighted as an isosurface of velocity. 


\section{Results}

PIV flowfield measurements were acquired for multiple operating conditions and forward rotor phase positions for the Historical Baseline blade set. Table 2 lists the data conditions and repeat measurement (23Aug10e). Figure 6 shows a representative data volume at one phase step. Two phase steps of the forward rotor were acquired for each operating condition so that the tip vortex would be captured in the higher radial resolution portion of the measurement grid for the entire axial extent of the vortex. This is a consequence of slicing a helical shaped flow feature with flat planes. Results from both phase steps are used to determine the vortex core trajectory. The resolution of the forward blade wake does not change with phase step so representative results are shown for one phase step only.

TABLE 2.-GENERAL TEST CONDITIONS

\begin{tabular}{|c|c|c|c|c|c|c|}
\hline $\begin{array}{c}\text { PIV data set } \\
\text { name }\end{array}$ & Blade set & $\begin{array}{c}\text { Model } \\
\text { config }\end{array}$ & $\begin{array}{c}\text { Blade pitch } \\
\text { angle, } \\
\text { Front/Aft }\end{array}$ & $\begin{array}{c}\text { Front } \\
\text { rotor, } \\
\text { rpm }\end{array}$ & $\begin{array}{c}\text { \#PIV measurement } \\
\text { planes }\end{array}$ & $\begin{array}{c}\text { Front rotor PIV } \\
\text { delay phase step }\end{array}$ \\
\hline 23Aug10a & F31/A31 & Take Off & $40.1^{\circ} / 40.8^{\circ}$ & 6444 & 30 & $0^{\circ}$ \\
\hline 23Aug10b & F31/A31 & Take Off & $40.1^{\circ} / 40.8^{\circ}$ & 6453 & 30 & $14.7^{\circ}$ \\
\hline 23Aug10c & F31/A31 & Take Off & $40.1^{\circ} / 40.8^{\circ}$ & 5680 & 30 & $0^{\circ}$ \\
\hline 23Aug10d & F31/A31 & Take Off & $40.1^{\circ} / 40.8^{\circ}$ & 5684 & 30 & $16.7^{\circ}$ \\
\hline 23Aug10e & F31/A31 & Take Off & $40.1^{\circ} / 40.8^{\circ}$ & 6452 & 24 & $0^{\circ}$ \\
\hline 25Aug10a & F31/A31 & Approach & $33.5^{\circ} / 35.7^{\circ}$ & 5704 & 30 & $0^{\circ}$ \\
\hline 25Aug10b & F31/A31 & Approach & $33.5^{\circ} / 35.7^{\circ}$ & 5707 & 30 & $18.1^{\circ}$ \\
\hline
\end{tabular}

\section{Tip Vortex Behavior}

The size, strength, trajectory and decay rate of the forward rotor tip vortex are all key parameters in assessing the acoustic influence of this flow feature on the system. For example, aft rotor clipping is a possible noise mitigation strategy in which the aft rotor is shortened sufficiently so that the tip vortex does not interact with the blade. However, aft clipping can have a negative impact on system efficiency so a minimal amount of clipping is desired to obtain the acoustic benefit without a substantial efficiency loss.

Several models for the tip vortex interaction have been developed. See Majjigi, et al. (Ref. 11) for one example of a model developed at GE. The GE model was developed based on analytical assumptions about the vortex and some limited experimental data. The data available at the time consisted of 1) helicopter rotor in hover data for the tip vortex trajectory and 2) data from finite span airfoils at angle of attack in a wind tunnel (for vortex decay). Neither of these data are necessarily representative of the vortex character and flow conditions experienced by counter rotating open rotors. Majjigi, et al. noted many times that the accuracy, completeness, and sophistication of the model can be extended with the inclusion of more representative data.

The tip vortex trajectory has been extracted from the current PIV data sets. The vortex core location was determined by looking at in-plane velocity vectors and in-plane streamlines as shown in Figure 7 for a specific axial location. The vortex core radial location is easily determined from this graphical view of the data. The process is repeated for additional axial planes until the vortex has moved outside of the PIV measurement volume. The accuracy of the location is assumed to be the spacing of the PIV measurement planes, either 0.1 or 0.2 in. at these locations. The geometric relationship between the PIV measurement coordinate system (shown in Fig. 10) and the open rotor model station coordinates is given in Table 3. 


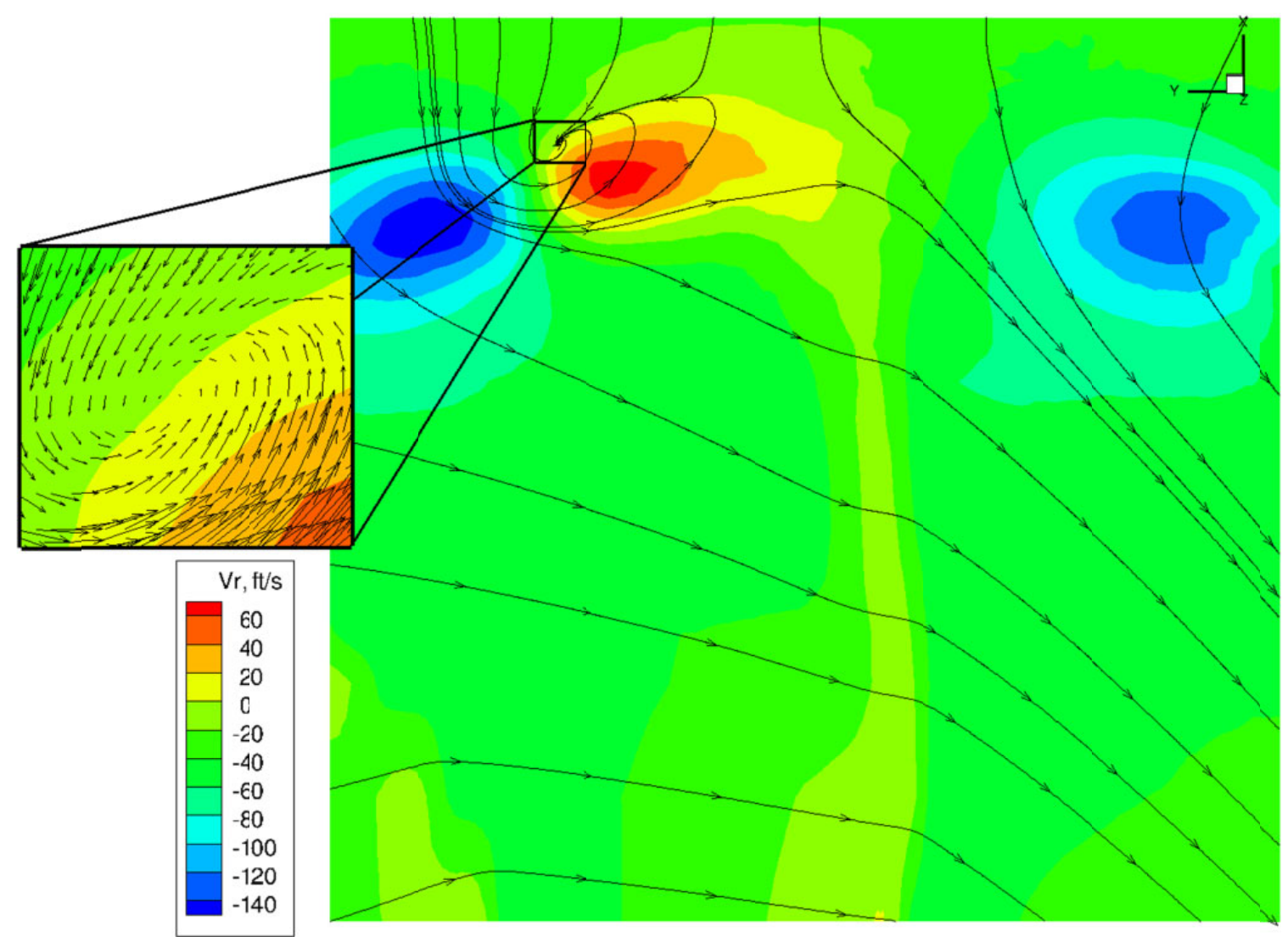

Figure 7.- Vortex core radial location can be determined from a combination of in-plane streamlines and inplane velocity vector plots at constant axial location slices through the PIV data volume. The vortex core radial location would be the center of rotation of the velocity vectors.

TABLE 3.-RELATIONSHIP BETWEEN PIV AND MODEL STATION (MSTA) COORDINATES

\begin{tabular}{|l|c|c|}
\hline \multicolumn{1}{|c|}{ Model location } & $\begin{array}{c}\text { MSTA, } \\
\text { in. }\end{array}$ & $\begin{array}{c}\text { Z, } \\
\text { in. }\end{array}$ \\
\hline Forebody nose & 166.943 & 0.00 \\
\hline F31 trailing edge tip & 194.254 & -27.31 \\
\hline & 194.943 & -28.00 \\
\hline & 195.943 & -29.00 \\
\hline Rtip $=12.9053$ in. & -------- & ------- \\
\hline
\end{tabular}

The vortex trajectory from Majjigi, et al. is reproduced here in Figure 8. The radial and axial location of the vortex core is normalized by the rotor tip radius. Note that there is much scatter in the data and a best fit line shows that the vortex core moves inward radially quickly and then its radial motion asymptotes. Figure 9 shows the trajectory of the tip vortex as extracted from the PIV measurements for both the Nominal Takeoff and Approach pitch angle settings. The data is normalized in the same way as in Figure 8 using the parameters listed in Table 3.

The vortex core trajectory has a substantially different character than that shown in Figure 8. The radial movement of the core is nearly linear with axial distance downstream, at least at the axial distances that are representative of typical rotor spacings. The asymptotic behavior is not present. The current PIV dataset unambiguously defines the vortex trajectory with greater certainty in vortex core location (less data scatter). The character and behavior of the tip vortex is not well represented by the model based on helicopter rotor data and the current dataset is important in establishing a canonical vortex trajectory for open rotors. 


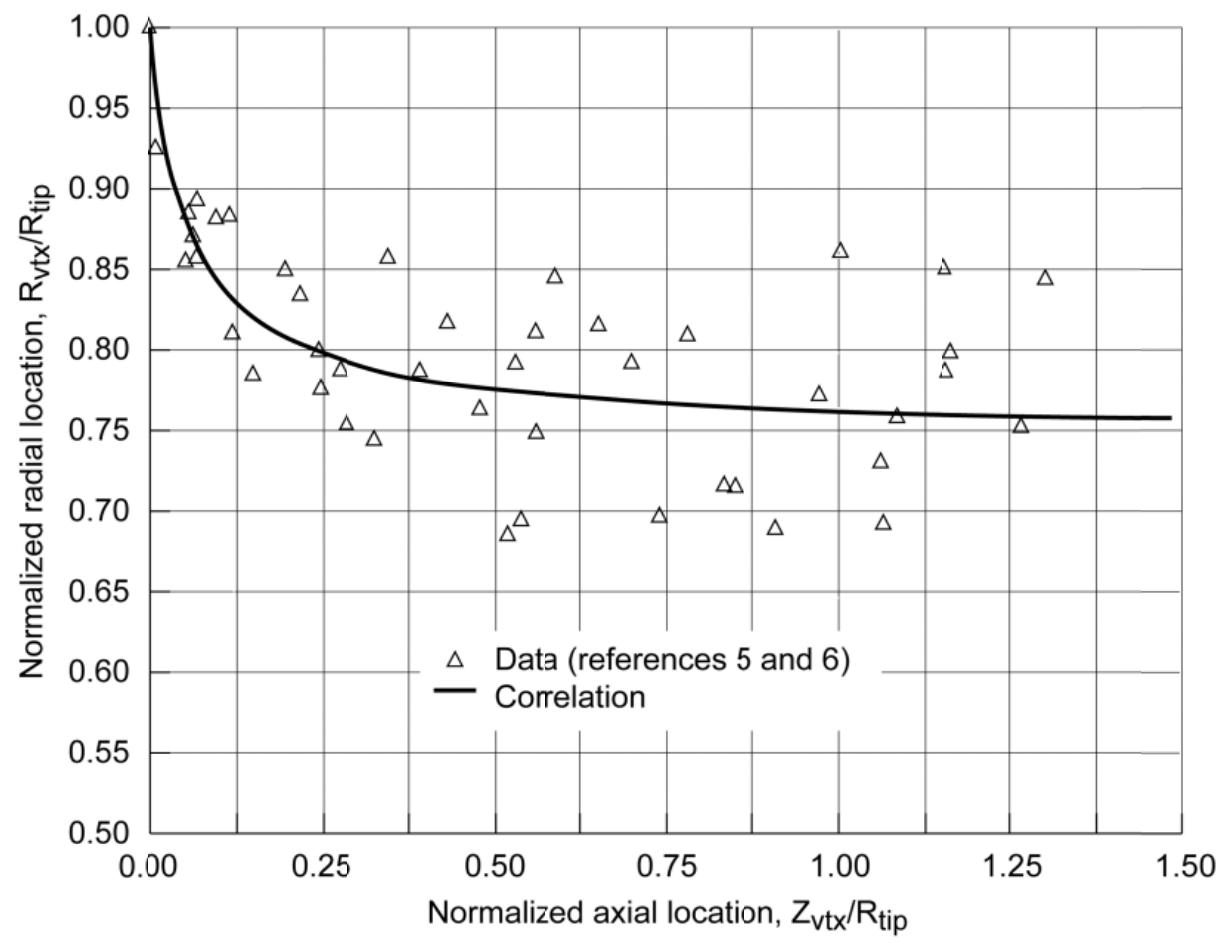

Figure 8.-Normalized vortex core radial location from Reference 11 (Figure 10 within the reference).

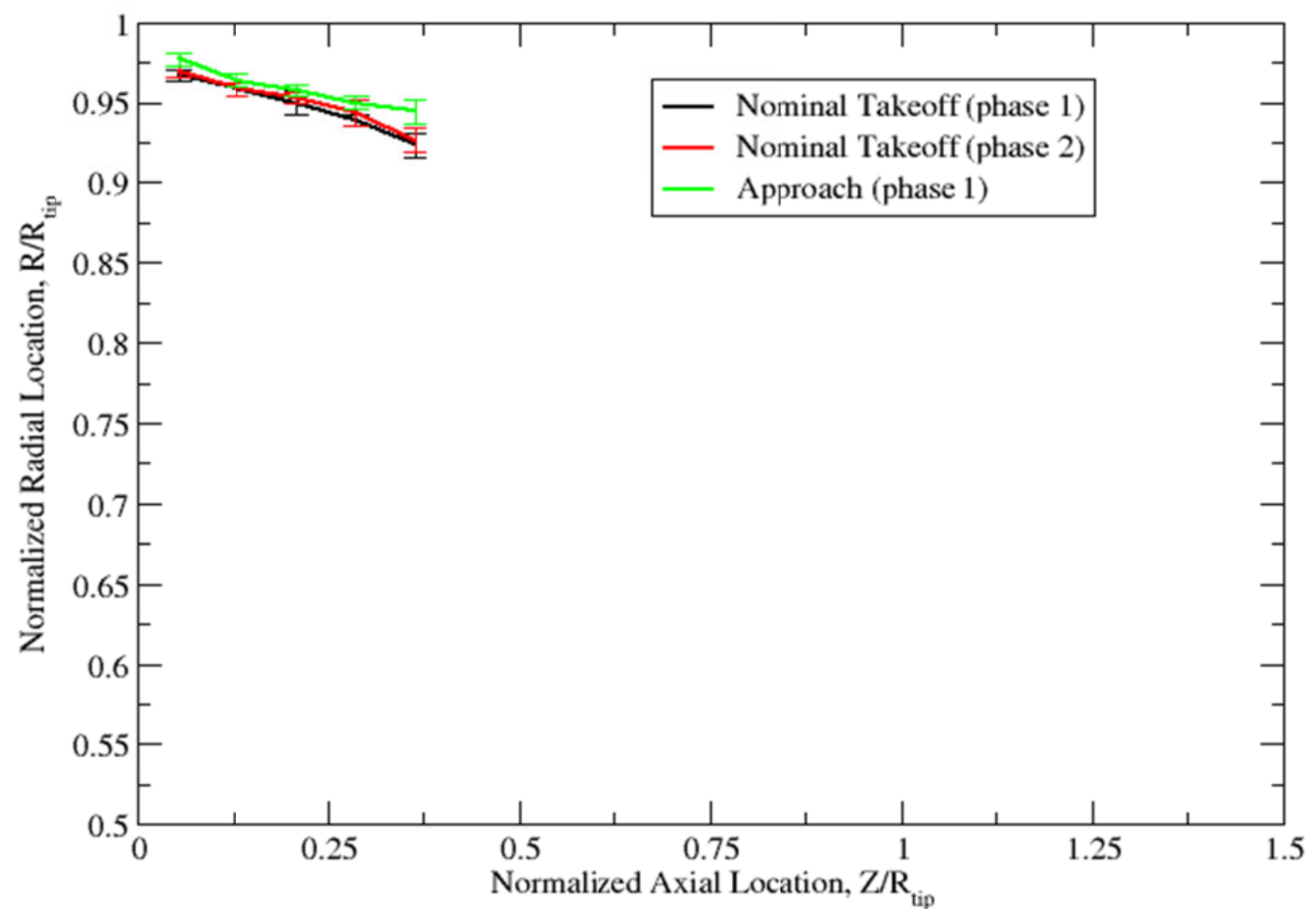

Figure 9.-Normalized vortex core radius determined from the PIV measurements. 
Additional information such as vortex core size and circulation can be determined from the PIV measurements. This additional analysis is beyond the scope of the current paper. Further analysis could improve the models developed in the 1980s with the intent of developing a more robust model suitable for guiding design decisions. The current data has been used to validate the design philosophy used for the advanced blades in the current test campaign.

\section{Wake Decay}

The shape, strength and turbulence character of the forward rotor wakes are key parameters in the wake generated tone and broadband noise signature of open rotors. Wake decay in turbomachines is caused by a combination of viscous effects, pressure gradient effects and wake stretching, References 12 and 13. A full assessment of these effects is beyond the scope of this paper, however representative wake profiles are extracted to show the quality of the data set.

Figure 10 shows the location of the extracted wake profiles and the orientation of the PIV coordinate system. The wake profiles are not along a constant radius but rather follow a PIV measurement plane to maintain the best spatial resolution. In the PIV coordinate system the wake profiles are at $X=9.13 \mathrm{in}$. and $\mathrm{X}=11.03 \mathrm{in}$. The cartesian velocity components have been transformed to cylindrical.

Figures 11 to 16 show the wake profiles at the two span locations in terms of axial, radial and tangential velocity. The $\sim 50$ percent span wake profiles ( $X=9.13$ in.), Figures 11,13 , and 15 , show the forward rotor wake clearly. The streamtube contraction caused by the thrust of the forward rotor is apparent as a uniform negative radial velocity. The outward migration of wake fluid is represented by a less negative radial velocity. The axial and tangential velocity profiles show the typical turbomachinery character; a deficit in axial velocity and an increase in tangential velocity within the wake region. Velocity profiles in the $\sim 75$ percent span locations $(X=11.03$ in.) are heavily influenced by the presence of the tip vortex and the velocity profiles do not show the classical behavior.

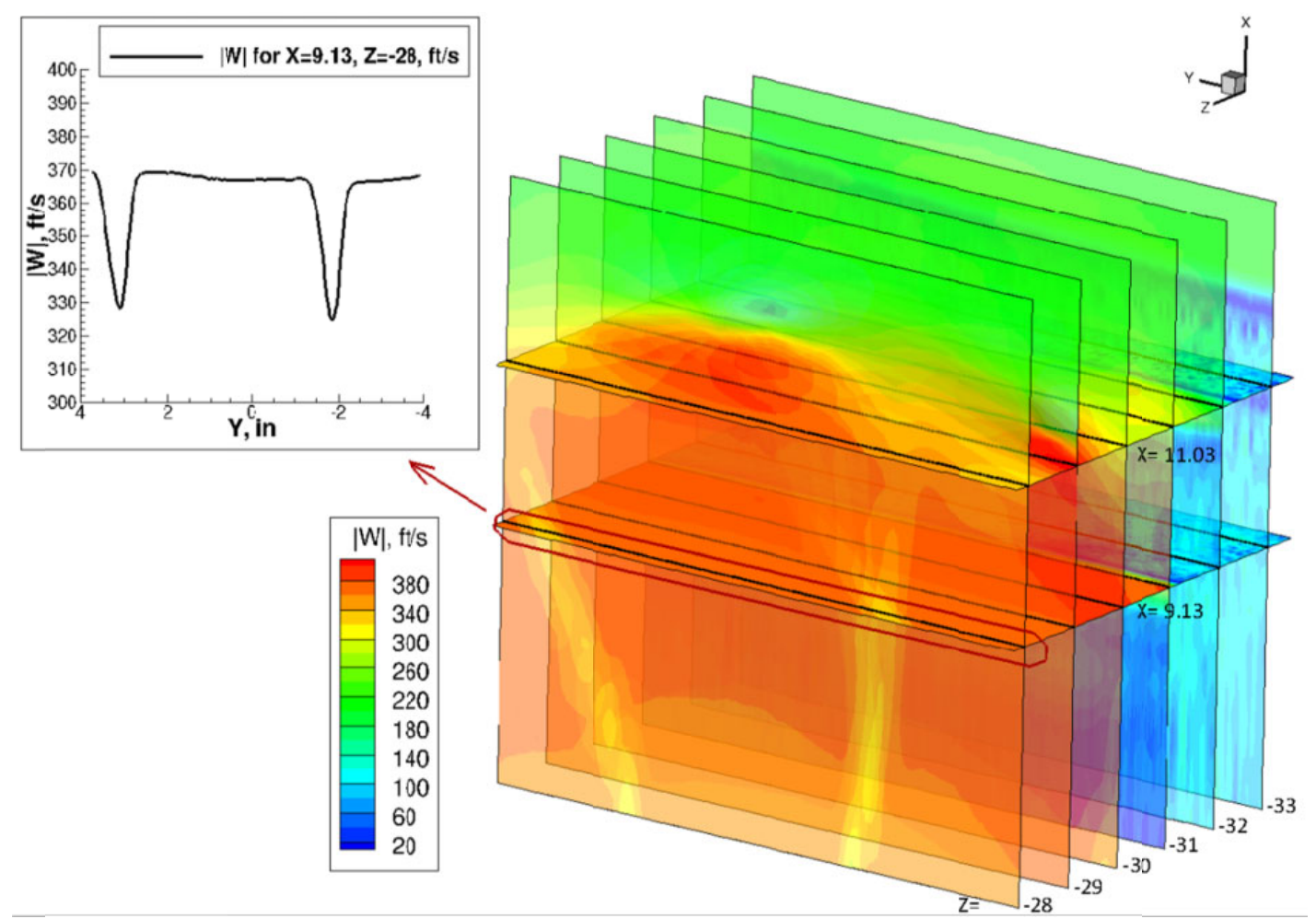

Figure 10.-Spatial location of wake velocity traces. Note these are along a constant $X$ location to maintain the best spatial resolution. 


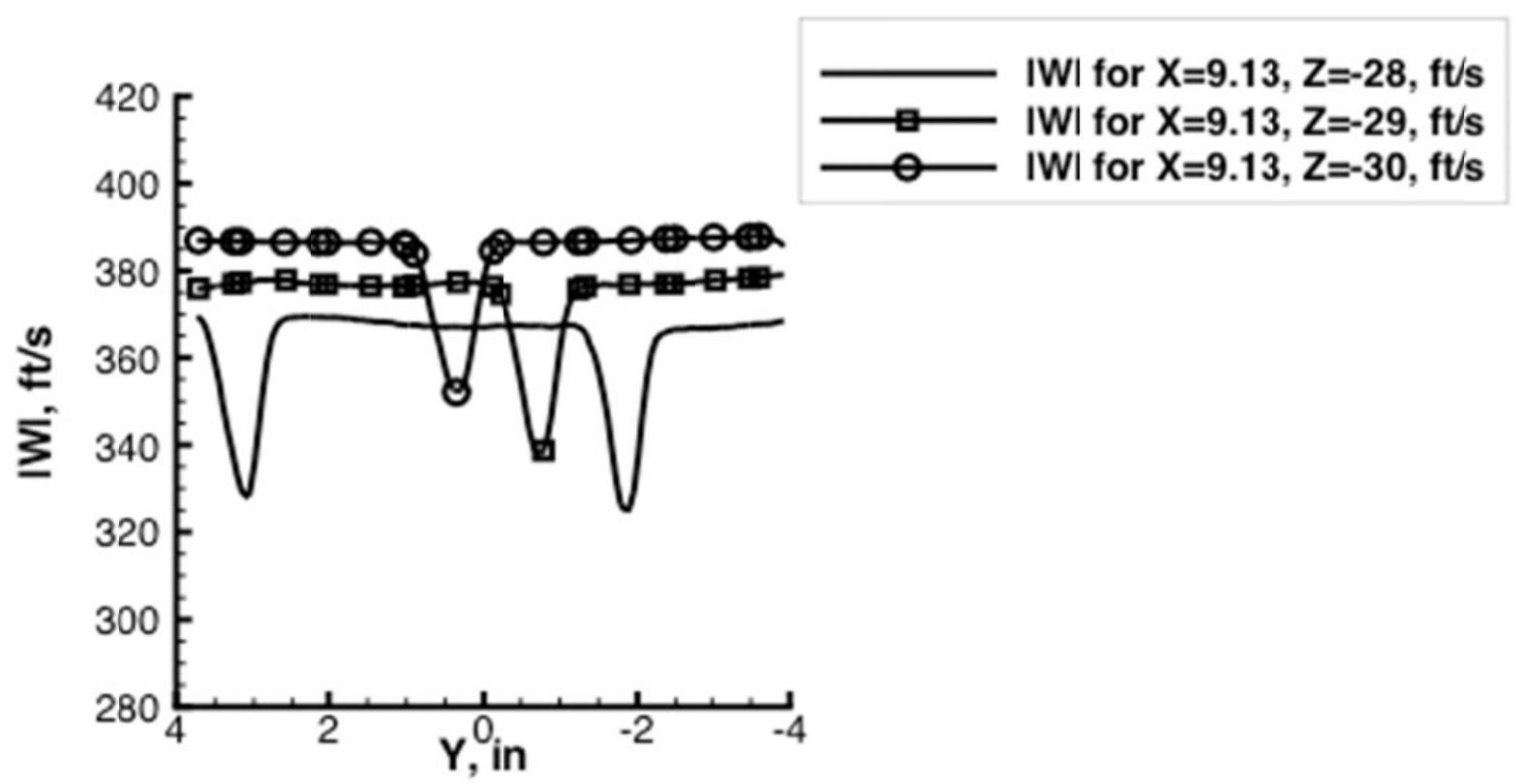

Figure 11.-Axial velocity wake profiles at the $\sim 50$ percent span location for three axial locations downstream of the forward blade.

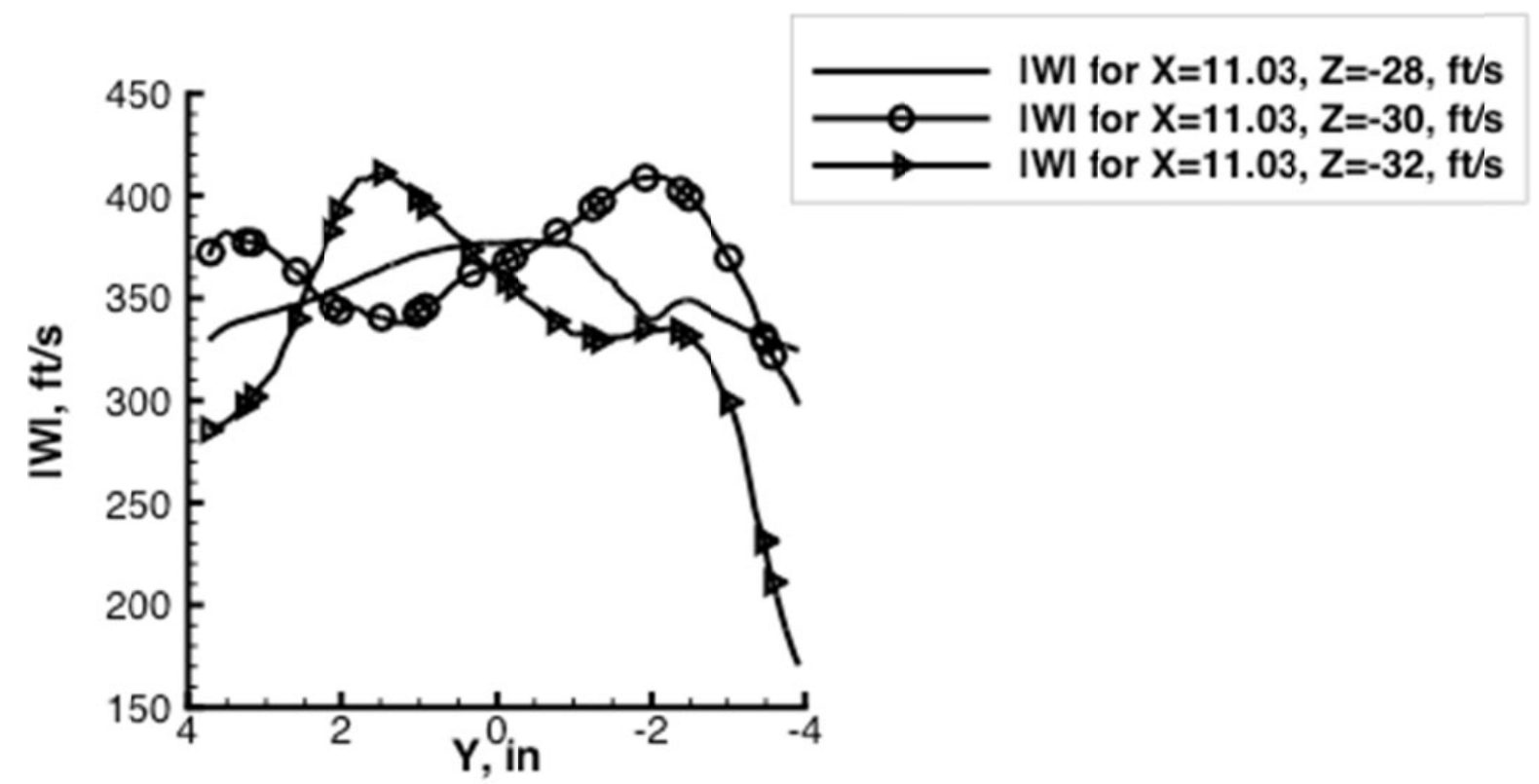

Figure 12.-Axial velocity wake profiles at the $\sim 75$ percent span location for three axial locations downstream of the forward blade. 

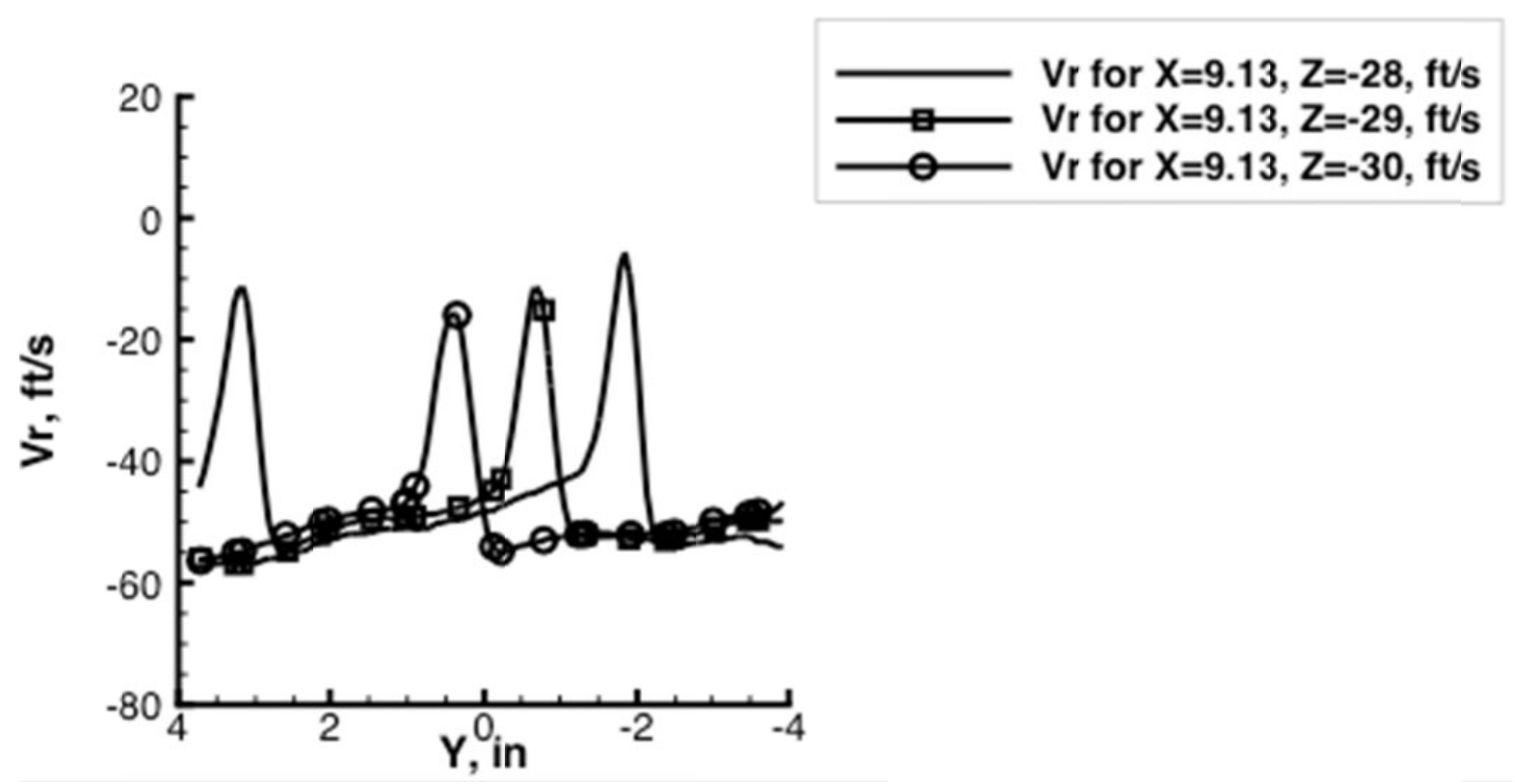

Figure 13.- Radial velocity wake profiles at the $\sim 50$ percent span location for three axial locations downstream of the forward blade.

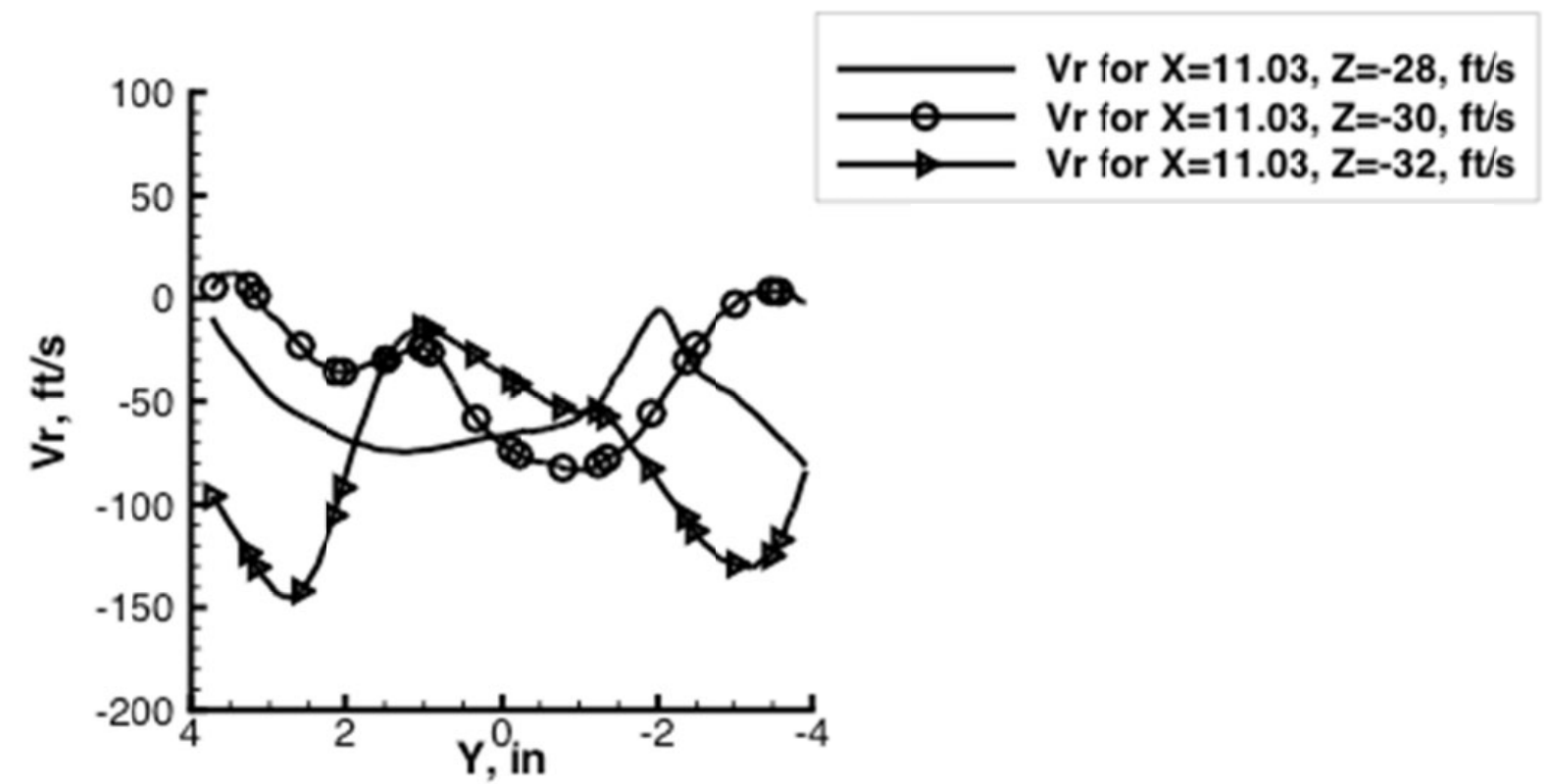

Figure 14.- Radial velocity wake profiles at the $\sim 75$ percent span location for three axial locations downstream of the forward blade. 


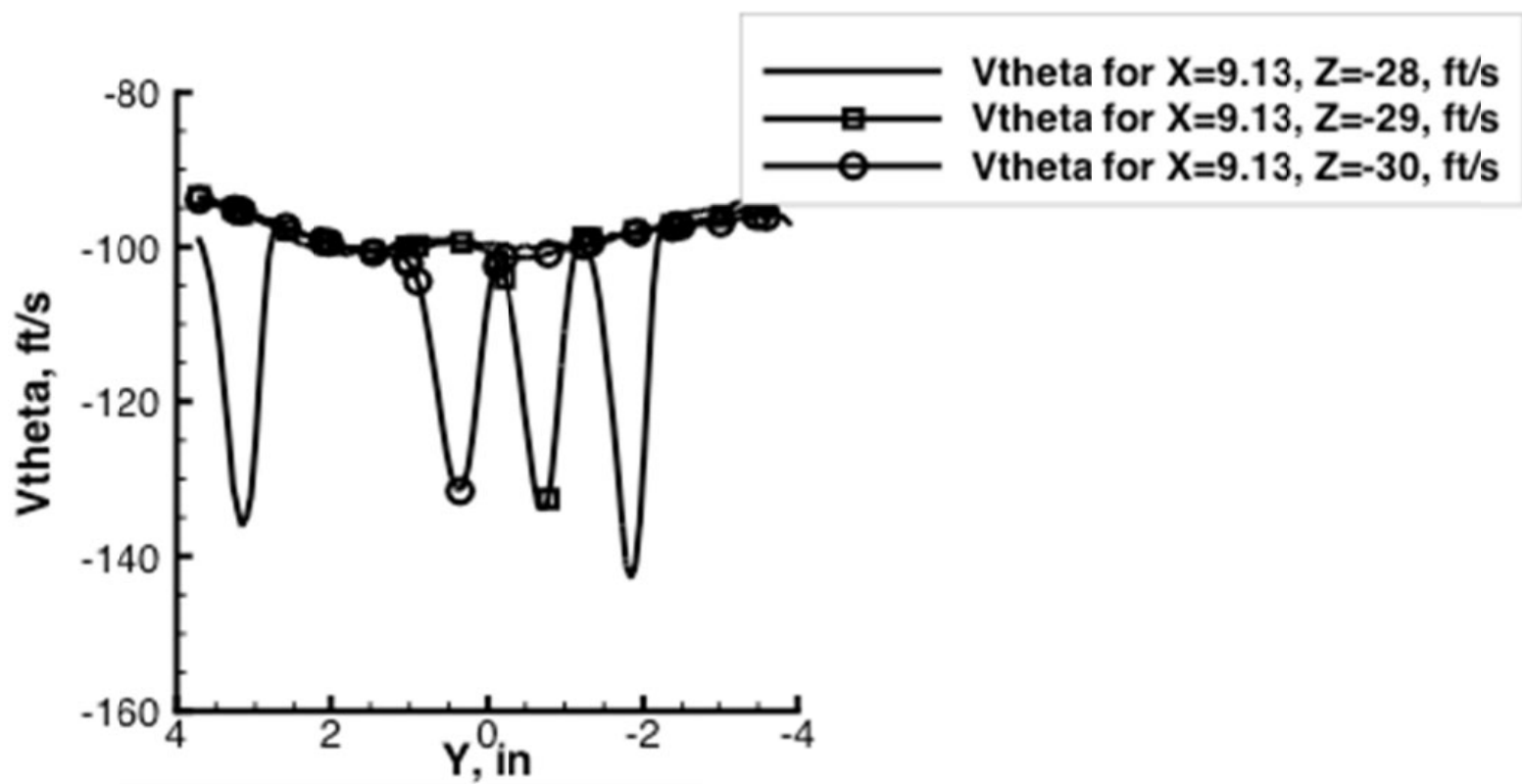

Figure 15.-Tangential velocity wake profiles at the $\sim 50$ percent span location for three axial locations downstream of the forward blade.

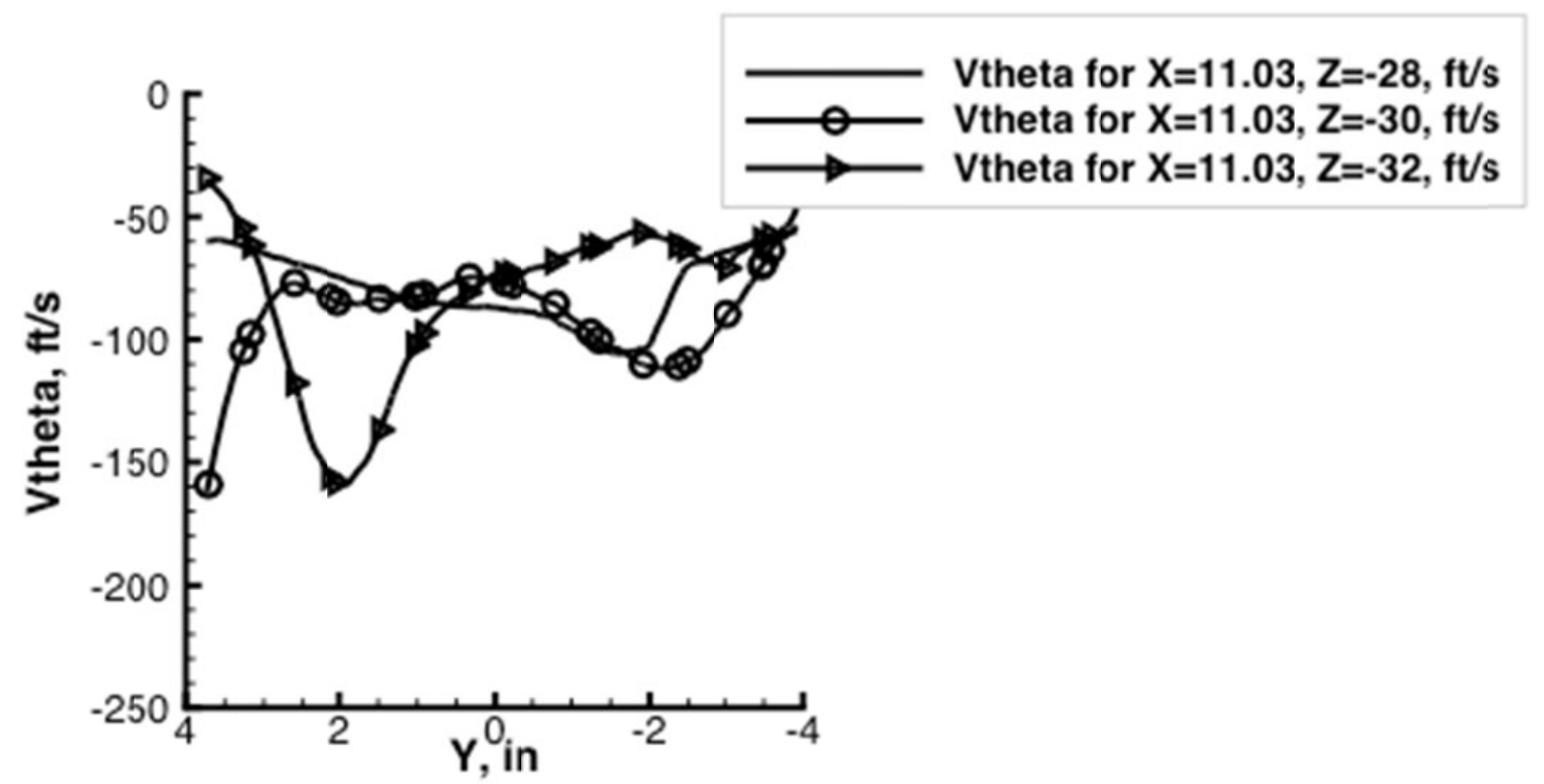

Figure 16.-Tangential velocity wake profiles at the $\sim 75$ percent span location for three axial locations downstream of the forward blade. 
The PIV data could be analyzed further to determine the relative importance of the sometimes competing effects of viscous decay and wake stretching. The turbulence character of the wake could also be analyzed to help guide broadband noise assessments.

\section{Summary}

A high quality, three dimensional velocity data set for counterrotating open rotors has been analyzed for tip vortex trajectory and rotor wake velocity profile characteristics. The tip vortex trajectory shows a linear character with axial distance. This is substantially different than the hyperbolic character derived from helicopter rotor measurements in the 1980s. The forward rotor wake profiles show the classical turbomachinery wake character for the more inboard span locations. The wake velocity character is heavily influenced by the tip vortex at the outer span locations and does not exhibit a classical wake behavior.

The data set is of sufficient resolution and quality that further analysis is warranted to determine the vortex core diameter and wake turbulence characteristics.

\section{References}

1. Woodward,, Richard P. and Hughes, Christopher E., "Acoustic Performance of the GEAE UPS Research Fan in the NASA Glenn 9- by 15-Foot Low-Speed Wind Tunnel,” NASA/TM-2012217450, May 2012.

2. Podboy, Gary G. and Krupar, Martin J., "Laser velocimeter measurements of the flow field generated by a forward-swept propfan during flutter,” NASA TM-106195, 1994

3. Woodward, R.P., Hall, D.G., Podboy, G.G., and Jeraki, R.J., "Takeoff/Approach Noise for a Model Counterrotation Propeller with a Forward-Swept Upstream Rotor,” AIAA-93-0596, presented at the 31st Aerospace Sciences Meeting \& Exhibit, Reno, NV, January 11-14, 1993.

4. Soloff, S.M., Adrian, R.J., and Liu, Z-C, "Distortion Compensation for Generalized Stereoscopic Particle Image Velocimetry,” Measurement Science and Technology, Vol. 8, No. 12, pp. 1441-1454, 1997.

5. Bjorkquist, D.C., "Design and Calibration of a Stereoscopic PIV System," Proc. 9th International Symposium on Applications of Laser Techniques to Fluid Mechanics, Vol. 1, pp. 6.5.1-6.5.8, Lisbon, Portugal, 1998.

6. Wernet, M. P., “Fuzzy Logic Enhanced Digital PIV Processing Software,” Proceedings of the $18^{\text {th }}$ International Congress on Instrumentation for Aerospace Simulation Facilities (ICIASF), Toulouse, France, June, 1999.

7. Gui, L., Werely, S.T., “A Correlation-Based Continuous Window-Shift Technique to Reduce The Peak-Locking Effect in Digital PIV Image Evaluation,” Exper. In Fluids, Vol. 32, pp. 506-517, 2002.

8. Westerweel, J., “Fundamentals of Digital Particle Image Velocimetry,” Meas. Sci. Technol., Vol. 8, pp. 1379-1392, 1997

9. Wernet, M.P., "Symmetric Phase Only Filtering: a New Paradigm for DPIV Data Processing," Meas. Sci. Technology, Vol. 16, pp. 601-618, 2005.

10. Taylor, J.R., An Introduction to Error Analysis, University Science Books, Oxford University Press, Mill Valley, CA., 1982.

11. Majjigi, R.K., Uenishi, K. and Gliebe, P.R., “An Investigation of Counterrotating Tip Vortex Interaction,” NASA CR-185135, 1989.

12. Hill, P.G., Schaub, U.W., and Senoo, Y., “Turbulent Wakes in Pressure Gradients,” ASME Journal of Applied Mechanics, Vol. 85, pp. 518-524, 1963.

13. Kool, P. and Hirsch, Ch., "A Prediction Scheme for the Decay of a Turbomachine Blade Wake,” ASME Paper No. 82-GT-273, 1982. 



\begin{tabular}{|c|c|c|}
\hline \multicolumn{2}{|c|}{ REPORT DOCUMENTATION PAGE } & $\begin{array}{l}\text { Form Approved } \\
\text { OMB No. 0704-0188 }\end{array}$ \\
\hline \multicolumn{3}{|c|}{ 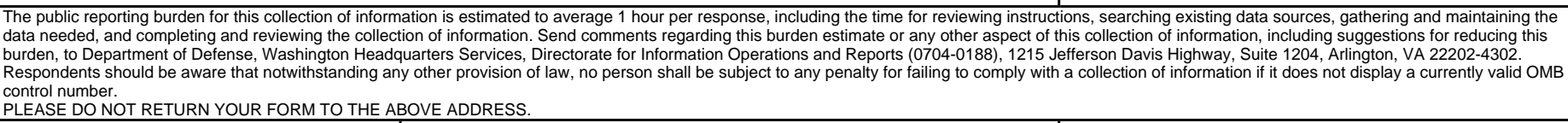 } \\
\hline $\begin{array}{l}\text { 1. REPORT DATE (DD-MM-YYYY) } \\
01-10-2012\end{array}$ & $\begin{array}{l}\text { 2. REPORT TYPE } \\
\text { Technical Memorandum }\end{array}$ & 3. DATES COVERED (From - To) \\
\hline \multirow{3}{*}{\multicolumn{2}{|c|}{$\begin{array}{l}\text { 4. TITLE AND SUBTITLE } \\
\text { Tip Vortex and Wake Characteristics of a Counterrotating Open Ro }\end{array}$}} & 5a. CONTRACT NUMBER \\
\hline & & 5b. GRANT NUMBER \\
\hline & & 5c. PROGRAM ELEMENT NUMBER \\
\hline \multirow{3}{*}{\multicolumn{2}{|c|}{$\begin{array}{l}\text { 6. AUTHOR(S) } \\
\text { Van Zante, Dale, E.; Wernet, Mark, P. }\end{array}$}} & 5d. PROJECT NUMBER \\
\hline & & 5e. TASK NUMBER \\
\hline & & $\begin{array}{l}\text { 5f. WORK UNIT NUMBER } \\
\text { WBS 699959.02.09.03.05 }\end{array}$ \\
\hline \multicolumn{2}{|c|}{$\begin{array}{l}\text { 7. PERFORMING ORGANIZATION NAME(S) AND ADDRESS(ES) } \\
\text { National Aeronautics and Space Administration } \\
\text { John H. Glenn Research Center at Lewis Field } \\
\text { Cleveland, Ohio 44135-3191 }\end{array}$} & $\begin{array}{l}\text { 8. PERFORMING ORGANIZATION } \\
\text { REPORT NUMBER } \\
\text { E-18418 }\end{array}$ \\
\hline \multirow{2}{*}{\multicolumn{2}{|c|}{$\begin{array}{l}\text { 9. SPONSORING/MONITORING AGENCY NAME(S) AND ADDRESS(ES) } \\
\text { National Aeronautics and Space Administration } \\
\text { Washington, DC 20546-0001 }\end{array}$}} & $\begin{array}{l}\text { 10. SPONSORING/MONITOR'S } \\
\text { ACRONYM(S) } \\
\text { NASA }\end{array}$ \\
\hline & & $\begin{array}{l}\text { 11. SPONSORING/MONITORING } \\
\text { REPORT NUMBER } \\
\text { NASA/TM-2012-217713 }\end{array}$ \\
\hline \multicolumn{3}{|c|}{$\begin{array}{l}\text { 12. DISTRIBUTIONIAVAILABILITY STATEMENT } \\
\text { Unclassified-Unlimited } \\
\text { Subject Category: } 07 \\
\text { Available electronically at http://www.sti.nasa.gov } \\
\text { This publication is available from the NASA Center for AeroSpace Information, 443-757-5802 }\end{array}$} \\
\hline
\end{tabular}

\section{SUPPLEMENTARY NOTES}

\section{ABSTRACT}

One of the primary noise sources for Open Rotor systems is the interaction of the forward rotor tip vortex and blade wake with the aft rotor. NASA has collaborated with General Electric on the testing of a new generation of low noise, counterrotating Open Rotor systems. Threedimensional particle image velocimetry measurements were acquired in the intra-rotor gap of the Historical Baseline blade set. The velocity measurements are of sufficient resolution to characterize the tip vortex size and trajectory as well as the rotor wake decay and turbulence character. The tip clearance vortex trajectory is compared to results from previously developed models. Forward rotor wake velocity profiles are shown. Results are presented in a form as to assist numerical modeling of Open Rotor system aerodynamics and acoustics.

\section{SUBJECT TERMS}

Aeroacoustics; Propeller noise; Noise reduction

\begin{tabular}{|c|c|c|c|c|c|}
\hline \multicolumn{3}{|c|}{ 16. SECURITY CLASSIFICATION OF: } & \multirow{2}{*}{$\begin{array}{l}\text { 17. LIMITATION OF } \\
\text { ABSTRACT } \\
\text { UU }\end{array}$} & \multirow{2}{*}{$\begin{array}{l}\text { 18. NUMBER } \\
\text { OF } \\
\text { PAGES } \\
24\end{array}$} & \multirow{2}{*}{$\begin{array}{l}\text { 19a. NAME OF RESPONSIBLE PERSON } \\
\text { STI Help Desk (email:help@sti.nasa.gov) } \\
\text { 19b. TELEPHONE NUMBER (include area code) } \\
\text { 443-757-5802 }\end{array}$} \\
\hline $\begin{array}{l}\text { a. REPORT } \\
U\end{array}$ & $\begin{array}{l}\text { b. ABSTRACT } \\
U\end{array}$ & $\begin{array}{l}\text { c. THIS } \\
\text { PAGE } \\
\text { U }\end{array}$ & & & \\
\hline
\end{tabular}



